This item was submitted to Loughborough's Research Repository by the author.

Items in Figshare are protected by copyright, with all rights reserved, unless otherwise indicated.

\title{
Numerical modeling of the spring thermal bar and pollutant transport in a large lake
}

PLEASE CITE THE PUBLISHED VERSION

http://dx.doi.org/10.1016/j.ocemod.2016.05.009

PUBLISHER

(C) Elsevier

VERSION

AM (Accepted Manuscript)

\section{PUBLISHER STATEMENT}

This work is made available according to the conditions of the Creative Commons Attribution-NonCommercialNoDerivatives 4.0 International (CC BY-NC-ND 4.0) licence. Full details of this licence are available at: https://creativecommons.org/licenses/by-nc-nd/4.0/

\section{LICENCE}

CC BY-NC-ND 4.0

\section{REPOSITORY RECORD}

Tsydenov, Bair O., Anthony Kay, and Alexander V. Starchenko. 2019. "Numerical Modeling of the Spring Thermal Bar and Pollutant Transport in a Large Lake". figshare. https://hdl.handle.net/2134/21754. 


\title{
NUMERICAL MODELING OF THE SPRING THERMAL BAR AND POLLUTANT TRANSPORT IN A
}

\section{LARGE LAKE}

\author{
Bair O. Tsydenov ${ }^{1, *}$, Anthony Kay ${ }^{2}$, Alexander V. Starchenko ${ }^{1}$ \\ ${ }^{1}$ Computational Geophysics Laboratory, Tomsk State University, Tomsk 634050, Russian Federation \\ ${ }^{2}$ Department of Mathematical Sciences, Loughborough University, Loughborough, LE11 3TU, UK
}

\begin{abstract}
The spring riverine thermal bar phenomenon is investigated numerically on an example of Lake Baikal, and the spread of pollutants coming from the Selenga River is forecast using the $2.5 D$ non-hydrostatic model in the Boussinesq approximation. This hydrodynamic model takes into account the diurnal variability of the heat fluxes on the lake surface and the effects of wind and the Earth's rotation. The results of numerical modeling show that the variability of the total heat flux over 24 hours plays a significant role in the variation of the thermal bar movement rate that contributes to the rapid mixing of impurities entering with river water.
\end{abstract}

\section{Highlights}

The proposed hydrodynamic model takes account of the diurnal variability of the meteorological factors.

The variable heat flux significantly influences thermal bar movement.

The thermal bar can move backwards to the shore due to nighttime cooling.

The pollutant propagation is closely correlated with the thermal bar development.

\section{Keywords}

thermal bar, mathematical model, temperature of maximum density, numerical experiment, Lake Baikal

\section{Introduction}

The clean water problem is one of the most important challenges posed by scientific and technological progress. Clean fresh water will become a resource of paramount importance in several decades (Danilov-Danilyan, 2009) because it is irreplaceable, in contrast to other natural resources. It is not the increased rate of water consumption but its contamination that leads to water depletion. The majority of inland fresh water is stored in lakes. Lake Baikal alone contains about $20 \%$ of the world's fresh water and over $80 \%$ of the fresh water of Russia. Understanding the natural mechanisms of the lake's hydrodynamics is essential to selecting an effective strategy to prevent water pollution. Predicting and monitoring the lake ecosystem create the possibility of assessing the scale of potential water reservoir contamination.

\footnotetext{
*Corresponding author. E-mail address: tsydenov@math.tsu.ru (B.O. Tsydenov)
} 
A phenomenon of particular importance for the dispersion of pollutants in many lakes including Baikal is the thermal bar, a downwelling plume which can form in spring and autumn as the surface temperature passes through the temperature of maximum density (Hubbard and Spain, 1973). In shallower lakes the thermal bar can mix the entire water column (Carmack, 1979), and it has been suggested that it may also be associated with deep water renewal in Baikal (Shimaraev et al., 1993); however, other mechanisms have now been proposed for deep water renewal (Schmid 15 et al., 2008).

Thermal bars may form due to meteorological forcing or river inflows, or a combination of these effects (Holland and Kay, 2003). As radiative and sensible heat fluxes into the lake increase in spring, the shallower regions near the shore will warm faster than deeper offshore regions (Elliott, 1971). Hence the $4^{\circ} \mathrm{C}$ (maximum density) isotherm will progress from the shore to the center of the lake. Similarly, the temperature of river water may increase 20 faster in spring than that of a lake, so the $4^{\circ} \mathrm{C}$ isotherm will progress from a river inflow towards the center of a lake in spring (Carmack, 1979). Again in autumn, the $4^{\circ} \mathrm{C}$ isotherm will appear at the shoreline or a river inflow and progress towards the center of a lake as shallow regions and river inflows cool down faster than the deep lake (Carmack et al., 1979).

The classical model of a thermal bar, established by Forel (1880), has water of maximum density sinking as a 25 narrow plume, with surface convergence towards the $4^{\circ} \mathrm{C}$ isotherm. However, buoyancy forces due to temperature variations are small near the temperature of maximum density, and while horizontal convergence will tend to sharpen temperature gradients, the dynamics of a thermal bar will be very sensitive to wind stress (especially in autumn when winds tend to be stronger) and small variations in mineralization of the water. Thus, the thermal bar may be a more diffuse feature than in Forel's concept: for example, Hubbard and Spain (1973) and Gbah and Murthy (1998) found regions of width around $2 \mathrm{~km}$ with strong horizontal temperature gradients either side of the $4^{\circ} \mathrm{C}$ isotherm in the Great Lakes of North America, but Malm et al. (1993) found that temperature gradients were no greater near the $4^{\circ} \mathrm{C}$ isotherm than elsewhere in Lake Ladoga. Vertical velocities are more difficult to measure, but Carmack and Farmer (1982) estimated sinking velocities of less than $10^{-4} \mathrm{~m} / \mathrm{s}$ in a thermal bar driven by surface cooling in autumn, but as high as $6 \times 10^{-2} \mathrm{~m} / \mathrm{s}$ in a riverine thermal bar.

Numerical modeling of the thermal bar has been carried out using 2D (Blokhina et al., 2001; Bocharov and Ovchinnikova, 1998; Farrow, 1995; Holland et al., 2001; Killworth et al., 1996; Kvon and Kvon, 1997; Vasiliev et al., 1998), 2.5D (Holland et al., 2003; Malm, 1995; Tsvetova, 1998), and 3D (Tsvetova, 1999) models. The choice of a model depends on the purpose of the study. Nevertheless, natural observations show that the main hydrodynamic and temperature changes take place from the shore to the lake center when the thermal bar forms and develops, while flow 40 characteristics are approximately homogeneous in the direction parallel to the shore. Based on this, it is considered that the physical process of riverine thermal bar development can be described accurately by a model in which all gradients 
in the direction parallel to the shore are excluded (Tsvetova, 1997); in particular, omission of the longshore pressure gradient is justified in a lake which is much longer than it is wide. Nevertheless, due to Coriolis force, the longshore velocity component may be of similar or larger magnitude than the other components; thus a $2.5 \mathrm{D}$ model in which all

45 three velocity components are retained is most suitable for studying thermal bar dynamics.

Various semi-empirical turbulence models are often used for numerical studies of the thermal bar (Bocharov and Ovchinnikova, 1998; Holland et al., 2003; Malm, 1995; Tsvetova, 1999). In particular, the vertical diffusion coefficient is calculated based on the Monin-Obukhov similarity theory (Tsvetova, 1999). Some (Killworth et al., 1996; Ovchinnikova and Bocharov, 2007) set turbulent diffusion coefficients as a constant. In recent times, two-equation

50 turbulence models have been used in simulations of the thermal bar (Tsvetova, 2011; Tsydenov and Starchenko, 2014). Vertical turbulent exchange processes have been either parameterized or calculated as per $k$ - $\varepsilon$ model (Tsvetova, 2011). There is a problem of very different coefficients of turbulent exchange along different directions with respect to the mean motion. Due to the steady density stratification, the vertical diffusion coefficients of momentum and scalars are smaller than the horizontal coefficients, which means that horizontal turbulent transport is greater than vertical turbulent

55 transport. Comparative analysis has been made (Tsydenov and Starchenko, 2014) of the algebraic model of Holland et al. (2003) and of the two parameter differential $k-\omega$ model of Wilcox (1988) showing their advantage over the $k-\varepsilon$ one for turbulent wall-adjacent flow modeling, using the thermal bar in Kamloops Lake, Canada, as an example. Numerical experiments showed that the $k-\omega$ turbulence model provides a more detailed picture of thermal bar development (Tsydenov and Starchenko, 2014). In this study, we apply the two-parameter k- $\omega$ model to calculate vertical turbulent 60 diffusion coefficients.

Circulations develop in a lake while water continuously interacts with the atmosphere. Heat transfer between the lake and the atmosphere arises through the radiative and turbulent heat fluxes (Ji, 2008). These fluxes play a crucial role in the formation of the thermal bar in the spring-summer period because they contribute to the warming of lake surface layers up to the temperature of maximum density, close to $4^{\circ} \mathrm{C}$. Usually, for thermal bar numerical modeling a

65 constant heat flux is set on the lake's free surface corresponding to the monthly mean value of the solar radiation (Holland et al., 2003; Lawrence et al., 2002). Tsvetova (1998) calculates the heat flux applying dependence on the horizontal coordinate $Q(x)=c-d \sin (\pi x / L)$, where $c=167.3 \mathrm{~J} /\left(\mathrm{m}^{2} \cdot s\right)$ corresponds to the mean values for June $(d=0.002, L$ is the length of the computational domain). A full understanding of how variations in meteorological conditions influence the dynamics of the thermal bar may require a model which includes parametrization of the detailed variation of shortwave and longwave radiation and latent and sensible heat fluxes over 24 hours, and consideration of the local temperature of the lake's upper layers.

The aim of the present paper is the numerical investigation of the development of the spring riverine thermal bar and its influence on lake water quality based on the 2.5D non-hydrostatic hydrodynamic model that considers daily 
variation of thermal and wind state of the atmosphere in the area where the Selenga River discharges its waters into

75 Lake Baikal, using the real morphometric, meteorological, and hydrochemical conditions.

\section{Numerical model}

\subsection{Governing equations}

The non-hydrostatic numerical model for the reproduction of hydrodynamic processes in a deep lake considering the effect of the Coriolis force related to the Earth's rotation and expressed in the

80 Boussinesq approximation includes the following equations (the process to be modeled is assumed to be homogenous along the direction across the river mouth - Oy axis; Ox axis is directed towards the lake, $O z$ is directed vertically upwards):

a) momentum equations

$$
\begin{aligned}
& \frac{\partial u}{\partial t}+\frac{\partial u^{2}}{\partial x}+\frac{\partial u w}{\partial z}=-\frac{1}{\rho_{0}} \frac{\partial p}{\partial x}+\frac{\partial}{\partial x}\left(K_{x} \frac{\partial u}{\partial x}\right)+\frac{\partial}{\partial z}\left(K_{z} \frac{\partial u}{\partial z}\right)+2 \Omega_{z} v-2 \Omega_{y} w \\
& \frac{\partial v}{\partial t}+\frac{\partial u v}{\partial x}+\frac{\partial w v}{\partial z}=\frac{\partial}{\partial x}\left(K_{x} \frac{\partial v}{\partial x}\right)+\frac{\partial}{\partial z}\left(K_{z} \frac{\partial v}{\partial z}\right)+2 \Omega_{x} w-2 \Omega_{z} u \\
& \frac{\partial w}{\partial t}+\frac{\partial u w}{\partial x}+\frac{\partial w^{2}}{\partial z}=-\frac{1}{\rho_{0}} \frac{\partial p}{\partial z}+\frac{\partial}{\partial x}\left(K_{x} \frac{\partial w}{\partial x}\right)+\frac{\partial}{\partial z}\left(K_{z} \frac{\partial w}{\partial z}\right)-\frac{g \rho}{\rho_{0}}+2 \Omega_{y} u-2 \Omega_{x} v
\end{aligned}
$$

b) continuity equation

$$
\frac{\partial u}{\partial x}+\frac{\partial w}{\partial z}=0
$$

c) energy equation

$$
\frac{\partial T}{\partial t}+\frac{\partial u T}{\partial x}+\frac{\partial w T}{\partial z}=\frac{\partial}{\partial x}\left(D_{x} \frac{\partial T}{\partial x}\right)+\frac{\partial}{\partial z}\left(D_{z} \frac{\partial T}{\partial z}\right)+\frac{1}{\rho_{0} c_{p}} \frac{\partial H_{s o l}}{\partial z}
$$

d) equations of salinity balance and pollutant concentration in the lake $(\Phi=S, C)$

$$
\frac{\partial \Phi}{\partial t}+\frac{\partial u \Phi}{\partial x}+\frac{\partial w \Phi}{\partial z}=\frac{\partial}{\partial x}\left(D_{x} \frac{\partial \Phi}{\partial x}\right)+\frac{\partial}{\partial z}\left(D_{z} \frac{\partial \Phi}{\partial z}\right)
$$

where $u, v$ are the horizontal velocity components along $O x$ and $O y$ axes, respectively; $w$ is the vertical velocity component; $\Omega_{x}, \Omega_{y}$, and $\Omega_{z}$ are the vector components of the Earth's rotation angular velocity; $g$ is the acceleration of gravity; $c_{p}$ is the specific heat capacity; $T$ is the temperature; $S$ is the salinity; $C$ is the pollutant concentration; $p$ is the

90 pressure; $\rho_{0}$ is the water density at standard atmospheric pressure; and temperature $T_{L}$ and salinity $S_{L}$ are a reference temperature and salinity of the lake, respectively. Absorption of shortwave radiation $H_{s o l}$ is calculated according to the Bouguer-Lambert-Beer law (see Section 2.4). 
The Chen-Millero equation (Chen and Millero, 1986) was taken as the equation of state $\rho=\rho(T, S, p)$. This equation relates water density to temperature, salinity, and pressure in the range $0 \leq T \leq 30^{\circ} \mathrm{C}, 0 \leq S \leq 0.6 \mathrm{~g} / \mathrm{kg}, 0 \leq$ $p \leq 180$ bar.

\subsection{Turbulence model}

To close the system of equations (1)-(6), a two-parameter $k-\omega$ model of turbulence developed by Wilcox (1988) is used. It consists of equations for turbulence kinetic energy and specific dissipation rate:

$$
\begin{gathered}
\frac{\partial k}{\partial t}+\frac{\partial u k}{\partial x}+\frac{\partial w k}{\partial z}=\frac{\partial}{\partial x}\left(\frac{v_{T}}{\sigma_{k}} \frac{\partial k}{\partial x}\right)+\frac{\partial}{\partial z}\left(\frac{v_{T}}{\sigma_{k}} \frac{\partial k}{\partial z}\right)+P+B-\varepsilon ; \\
\frac{\partial \omega}{\partial t}+\frac{\partial u \omega}{\partial x}+\frac{\partial w \omega}{\partial z}=\frac{\partial}{\partial x}\left(\frac{v_{T}}{\sigma_{\omega}} \frac{\partial \omega}{\partial x}\right)+\frac{\partial}{\partial z}\left(\frac{v_{T}}{\sigma_{\omega}} \frac{\partial \omega}{\partial z}\right)+\frac{\omega}{k}\left(c_{\omega 1} P+c_{\omega 3} B-c_{\omega 2} \varepsilon\right),
\end{gathered}
$$

100 where $k$ is the turbulence kinetic energy; $\omega$ is the specific dissipation rate; $v_{T}=\frac{k}{\omega}$ is the turbulent kinematic viscosity; and $\sigma_{k}, \sigma_{\omega}$ are the turbulent Schmidt numbers for $k$ and $\omega$, respectively. The numerical parameters of equations (7) and (8) are presented in Table 1.

Table 1 - Parameters of $k-\omega$ turbulence model

\begin{tabular}{|c|c|c|c|c|c|c|}
\hline Model constant & $\mathrm{c}_{\omega 1}$ & $\mathrm{c}_{\omega 2}$ & $\mathrm{c}_{\omega 3}$ & $\sigma_{k}$ & $\sigma_{\omega}$ & $\left(\mathrm{c}_{\mu}{ }^{0}\right)^{2}$ \\
\hline Value & 0.555 & 0.833 & $\begin{array}{c}0.755(B>0) \\
-1(B<0)\end{array}$ & 2 & 2 & 0.307 \\
& & & & & \\
\hline
\end{tabular}

105 The term $\varepsilon=\left(c_{\mu}^{0}\right)^{4} k \omega$ in (7) - (8) denotes viscous dissipation of turbulence energy, and $P$ and $B$, turbulence generation due to the shear stresses and buoyancy force:

$$
\begin{gathered}
P=v_{T}\left[2\left(\frac{\partial u}{\partial x}\right)^{2}+2\left(\frac{\partial w}{\partial z}\right)^{2}+\left(\frac{\partial u}{\partial z}+\frac{\partial w}{\partial x}\right)^{2}+\left(\frac{\partial v}{\partial x}\right)^{2}+\left(\frac{\partial v}{\partial z}\right)^{2}\right] \\
B=-\frac{v_{T}}{\operatorname{Pr}_{T}} N^{2}\left(\operatorname{Pr}_{T}=1\right),
\end{gathered}
$$

where $N^{2}$ is the Brunt-Väisälä (buoyancy) frequency defined by

$$
N^{2}=g \alpha\left(\frac{\partial T}{\partial z}-\Gamma\right)
$$

where $\Gamma=-\frac{g \alpha}{c_{p}}\left(T_{C}+273.15\right)$ is the adiabatic temperature gradient. 
The vertical diffusion coefficients for momentum and scalars are calculated as

$$
\begin{gathered}
K_{z}=v_{T}+v, \\
D_{z}=\frac{v_{T}}{\operatorname{Pr}_{T}}+\frac{v}{\operatorname{Pr}},
\end{gathered}
$$

115 where $v$ is the molecular kinematic viscosity of water; and $\operatorname{Pr}, \operatorname{Pr}_{T}$ are the molecular and turbulent Prandtl numbers.

The horizontal diffusion coefficients are assumed to be constant (Holland et al., 2003):

$$
K_{x}=D_{x}=2.5 \mathrm{~m}^{2} / \mathrm{s}
$$

\subsection{Initial and boundary conditions}

Initial conditions for equations (1)-(8) are set as follows:

$$
u=0 ; v=0 ; w=0 ; T=T_{L} ; S=S_{L} ; C=0 ; k=0 ; \omega=\omega_{0} \text { at } t=0,
$$

where $T_{L}, S_{L}$ are the temperature and salinity in the lake, respectively, and $t$ is the time. The initial pressure field is specified by solving the state and hydrostatic equations with the boundary condition $p=p_{a}$ on the surface ( $p_{a}$ is the atmospheric pressure) by a fourth-order Runge-Kutta method. The hydrostatic equation is derived from equation (3) with $u=v=w=0$ as follows:

$$
\frac{\partial p}{\partial z}=-\rho g
$$

The motionless initial condition requires the retention of the molecular contributions to the vertical diffusion coefficients in (7) and (8).

Boundary conditions for equations (1)-(8) are

130 a) at the free surface

$$
K_{z} \frac{\partial u}{\partial z}=\frac{\tau_{\text {surf }}^{u}}{\rho_{0}} ; K_{z} \frac{\partial v}{\partial z}=\frac{\tau_{\text {surf }}^{v}}{\rho_{0}} ; w=0 ; D_{z} \frac{\partial T}{\partial z}=\frac{H_{n e t}}{\rho_{0} \cdot c_{p}} ; \frac{\partial S}{\partial z}=0 ; \frac{\partial C}{\partial z}=0 ; \frac{\partial k}{\partial z}=0 ; \frac{\partial \omega}{\partial z}=\frac{\sqrt{k}}{c_{\mu}^{0} \kappa\left(L_{z}-z+z_{0}\right)^{2}}
$$

where $H_{n e t}$ is the heat flux of longwave radiation, latent, and sensible heat (see Section 2.4 ), W/m $\mathrm{m}^{2} \kappa=0.41$ is the von Karman constant; and $z_{o}=0.5 \mathrm{~m}$ is the roughness height. The wind shear stress on the lake surface is described according to the law

$$
\begin{gathered}
\tau_{\text {surf }}^{u}=c_{10} \rho_{a} \sqrt{v_{10}^{2}+u_{10}^{2}} \cdot u_{10} ; \\
\tau_{\text {surf }}^{v}=c_{10} \rho_{a} \sqrt{v_{10}^{2}+u_{10}^{2}} \cdot v_{10},
\end{gathered}
$$


where $\rho_{a}$ is the air density at the water surface; $u_{10}, v_{10}$ are the wind velocity components at $10 \mathrm{~m}$ above the lake surface; $c_{10}=1.3 \times 10^{-3}$;

b) at the solid boundaries (the bottom)

$$
u=0 ; v=0 ; w=0 ; D_{z} \frac{\partial T}{\partial n}=-\frac{H_{g e o}}{\rho_{0} c_{p}} ; \frac{\partial S}{\partial n}=0 ; \frac{\partial C}{\partial n}=0 ; \frac{\partial k}{\partial n}=0 ; \frac{\partial \omega}{\partial n}=-\frac{\sqrt{k}}{c_{\mu}^{0} \kappa\left(z+z_{0}\right)^{2}},
$$

where $H_{g e o}=0.1 \mathrm{~W} / \mathrm{m}^{2}$ is the geothermal heat flux; $n$ is the direction of the outward normal to the domain; and $z_{o}=0.05$ m;

c) at the river inflow boundary $(x=0,-15<z<0)$

$$
u=u_{R} ; v=0 ; w=0 ; T=T_{R} ; S=S_{R} ; C=1 ; k=k_{R} ; \omega=\omega_{R},
$$

145 where $u_{R}$ is the river inflow velocity; and $T_{R}, S_{R}, k_{R}$, and $\omega_{R}$ are the temperature, salinity, turbulence kinetic energy, and turbulent fluctuation frequency in the river, respectively. The initial values for turbulence kinetic energy and turbulent fluctuation frequency in the river are determined on the basis of the isotropy of turbulence and the turbulence intensity of $30 \%$.

d) at the open boundary, conditions of the radiation type (Orlanski, 1976) are set:

$$
\frac{\partial \phi}{\partial t}+c_{\phi} \frac{\partial \phi}{\partial x}=0(\phi=u, v, T, S, C) ; \frac{\partial w}{\partial x}=0 ; \frac{\partial k}{\partial x}=0 ; \frac{\partial \omega}{\partial x}=0,
$$

the phase velocity $c_{\phi}$ is calculated here from the space and time trends $\phi$ in the domain near the boundary.

\subsection{Parameterization of heat fluxes on the free surface}

Heat exchange between the lake and atmosphere takes place by means of radiative and turbulent heat fluxes. These fluxes play the most important role in the formation of the spring-summer thermal bar by heating the lake surface layers to the temperature of maximum density (Tsydenov and Starchenko, 2015). In this paper, to parameterize the heat fluxes at the water-air interface, we propose a combined model with formulas to calculate the longwave radiation $\left(H_{l w}\right.$; Hodges, 1998) and fluxes of latent $\left(H_{L}\right)$ and sensible $\left(H_{S}\right)$ heat (Goudsmit et al., 2002):

$$
H_{l w}=\varepsilon_{a} \sigma\left(1-r_{A}\right)\left(1+0.17 \gamma^{2}\right) T_{A}^{4}-\varepsilon_{w} \sigma T^{4}
$$

where $T_{A}$ is the air temperature, $\mathrm{K} ; T$ is the water temperature, $\mathrm{K} ; \gamma$ is the cloud amount as a fraction; $\sigma=5.669 \times 10^{-8}$ $\mathrm{W} / \mathrm{m}^{2} / \mathrm{K}^{4}$ is the Stefan-Boltzmann constant; $r_{A}=0.03$ is the coefficient of incoming radiation reflection from the water surface; and $\varepsilon_{w} \approx 0.96$ is the water emissivity. The atmospheric emissivity is calculated by the formula

$$
\varepsilon_{a}=C_{\varepsilon} T_{A}^{2},
$$

where $C_{\varepsilon}=9.37 \times 10^{-6}{ }^{\circ} \mathrm{C}^{-2}$ is the emissive power of air; 


$$
\begin{gathered}
H_{L}=f_{u}\left(e_{A}-e_{w}\right) ; \\
f_{u}=4.4+1.82 \cdot U_{10}+0.26\left(T-T_{A}\right) ; \\
e_{w}=f_{w} \times 10^{\frac{0.7859+0.03477 T}{1+0.00412 T}} ; \\
f_{w}=\beta \cdot\left(1+10^{-6} p_{a}\left(4.5+6 \cdot 10^{-5} T^{2}\right),\right.
\end{gathered}
$$

where $e_{w}$ is the pressure of saturated water vapor, $\mathrm{hPa} ; e_{A}=0.01 \cdot R H \cdot e_{w}$ is the pressure of water vapor in the atmosphere,

$165 \mathrm{hPa} ; R H$ is the relative humidity, $\% ; f_{u}$ is the heat-transfer coefficient, $\mathrm{W} / \mathrm{m}^{2} / \mathrm{hPa} ; U_{10}=\sqrt{u_{10}^{2}+v_{10}^{2}}$ is the wind velocity, $\mathrm{m} / \mathrm{s} ; p_{a}=1013 \mathrm{hPa}$ is the standard atmospheric pressure; and $\beta=0.61 \mathrm{hPa} / \mathrm{K}$;

$$
H_{S}=\beta \cdot f_{u}\left(T_{A}-T\right)
$$

The total heat flux $H_{\text {net }}$ is

$$
H_{n e t}=H_{l w}+H_{L}+H_{S},
$$

where $H_{l w}$ is the longwave radiation; and $H_{L}, H_{S}$ are the fluxes of latent and sensible heat, respectively.

It should be noted that the flux $H_{\text {net }}$ is given on the free surface for the temperature equation. It does not include 170 shortwave radiation, since that is taken into account in the source term of the energy equation (5). The absorption of shortwave radiation $H_{\text {sol }}$ is calculated according to the Bouguer-Lambert-Beer law (Goudsmit et al., 2002):

$$
H_{s o l}=H_{S s o l, 0}\left(1-r_{s}\right) \exp \left(-\varepsilon_{a b s}\left|L_{z}-z\right|\right)
$$

where $r_{s} \approx 0.2$ is the water reflection coefficient, and $\varepsilon_{a b s} \approx 0.3 \mathrm{~m}^{-1}$ is the absorption coefficient of solar radiation in water. The influx of solar radiation at the lake surface $H_{S s o l, 0}$ is calculated from the following relation (Hurley, 2002):

$$
H_{S s o l, 0}= \begin{cases}S_{0} \cdot\left(a_{g}-a_{w}\right) \cdot \cos \zeta[a(C)+b(C) \ln (\cos \zeta)], & \text { if } \cos \zeta>0 \\ 0, & \text { if } \cos \zeta \leq 0\end{cases}
$$

where $S_{0} \approx 1367 \mathrm{~W} / \mathrm{m}^{2}$ is the solar constant, $a(C)$ and $b(C)$ are empirical coefficients (Aleksandrova et al., 2007), $\zeta$ is the Solar zenith angle, and the empirical functions

$$
\begin{gathered}
a_{g}=0.485+0.515 \cdot(1.014-0.16 / \sqrt{\cos \zeta}), \\
a_{w}=0.039 \cdot\left(r_{w} / \cos \zeta\right)^{0.3}
\end{gathered}
$$

represent respectively molecular scattering and absorption by permanent gases (e.g. oxygen); and $r_{w}$ is the water vapor content in the atmosphere, $\mathrm{kg} / \mathrm{m}^{2}$. 


\section{Numerical method}

The above-formulated problem is solved by a finite volume method. The scalar quantities (temperature, salinity, etc.) are calculated in the center of a grid cell while the velocity vector components are at the mid-points of the

185 cell boundaries. To approximate the computational domain to the lake coastal profile, a method of blocking of fictitious domains (Patankar, 1980) is used: the velocity components below the lake bed are set to zero by using large values of the viscosity coefficients in this zone.

The numerical algorithm for finding the flow and temperature fields is based on a Crank-Nicholson difference scheme. The convective terms in the equations are approximated with a second-order upstream scheme, QUICK (Leonard, 1979). To adjust the velocity and pressure fields calculated by the model, an original procedure for buoyant flows, SIMPLED (Semi-Implicit Method for Pressure Linked Equations with Density correction), which is a modification of Patankar's method SIMPLE (Patankar, 1980), has been developed. SIMPLED corrects velocity and pressure fields with account to the variation of density in the gravitational term of equation (3).

The algorithm of SIMPLED is based on a cyclic "prediction-correction" sequence:

195 1. Set approximate fields of pressure $p^{*}$, temperature $T^{*}$, and salinity $S^{*}$.

2. Solve the momentum equations to obtain approximate values of the velocity components $u^{*}$ and $w^{*}$ from the equations (here we use the notation adopted in Patankar, 1980):

$$
\begin{gathered}
a_{e}^{u} u_{e}^{*}=\sum_{n b} a_{n b}^{u} u_{n b}^{*}+b^{u}+\left(p_{P}^{*}-p_{E}^{*}\right) h_{z} ; \\
a_{n}^{w} w_{n}^{*}=\sum_{n b} a_{n b}^{w} w_{n b}^{*}+b^{w}+\left(p_{P}^{*}-p_{N}^{*}\right) \Delta x-\frac{\rho_{n}^{*} g}{\rho_{0}} h_{x} \cdot h_{z},
\end{gathered}
$$

where $\sum_{n b}$ is the summation over all neighboring finite-volume nodes $W, E, S$, and $N ; h_{x}$ and $h_{z}$ are grid steps in the corresponding directions.

3. Solve the equations for energy (to obtain $T$ ) and salinity (to obtain $S$ ) and calculate $\rho^{\prime}=\rho\left(p^{*}, T, S\right)-\rho\left(p^{*}, T^{*}, S^{*}\right)$

4. Solve the pressure correction $p^{\prime}$ equations

$$
a_{P} p_{P}^{\prime}=a_{E} p_{E}^{\prime}+a_{W} p_{W}^{\prime}+a_{N} p_{N}^{\prime}+a_{S} p_{S}^{\prime}+b
$$

where $a_{E}=d_{e} h_{z}, \quad a_{W}=d_{w} h_{z}, \quad a_{N}=d_{n} h_{x}, a_{S}=d_{s} h_{x}, a_{P}=a_{E}+a_{W}+a_{N}+a_{S}$,

$$
b=\left(u_{w}^{*}-u_{e}^{*}\right) h_{z}+\left(w_{s}^{*}-w_{n}^{*}\right) h_{x}+\frac{g}{\rho_{0}}\left(c_{n} \rho_{n}^{\prime}-c_{s} \rho_{s}^{\prime}\right) h_{x} .
$$

5. Calculate $p$ by adding $p^{\prime}$ to $p^{*}$. 
6. Correct the velocity components $u$ and $w$ from the formulas

$$
\begin{gathered}
u_{e}=u_{e}^{*}+d_{e}\left(p_{P}^{\prime}-p_{E}^{\prime}\right) ; \\
w_{n}=w_{n}^{*}+\left(p_{P}^{\prime}-p_{N}^{\prime}\right) d_{n}-\frac{\rho_{n}^{\prime} g}{\rho_{0}} c_{n},
\end{gathered}
$$

where $d_{e}=\frac{h_{z}}{a_{e}^{u}}, d_{n}=\frac{h_{x}}{a_{n}^{w}}, c_{n}=\frac{h_{x} \cdot h_{z}}{a_{n}^{w}}$.

7. Solve the equations for energy, salinity, and momentum for $v$ and calculate $\rho=\rho(p, T, S)$.

Go to step 2 and repeat the calculations until convergence is reached. The SIMPLED procedure allows

215 increase of the time step twice in comparison to SIMPLE. The systems of grid equations at each time step are solved by the under-relaxation method.

The numerical algorithm has been tested by modeling of seasonal circulations in Kamloops Lake (Tsydenov and Starchenko, 2013). Computational experiments performed for scenarios "Winter", "Early Spring", "Middle Spring", and "Late Spring" (Tsydenov and Starchenko, 2013) demonstrated good agreement with patterns of interaction 220 in the river-lake system described by Carmack et al. (1979) on the basis of field observations in Kamloops Lake.

\section{Results and Discussion}

\subsection{Domain morphometry and numerical calculations}

The Srednyaya arm (Selenga mouth)-the Buguldeika cross-section, near the boundary between the southern 225 and central basins of Lake Baikal (Siberia, Russia), was taken for the study. Bottom topography data for this crosssection (Fig. 1) (Tsydenov et al., 2015) were taken from a bathymetrical electronic map of Lake Baikal (Sherstyankin et al., 2006). The Selenga shallow water basin is located between $51.9^{\circ}-52.5^{\circ} \mathrm{N}$. and $106.1^{\circ}-106.9^{\circ}$ E.: from the southern part of Istoksky Sor to Cape Oblom. 
(a)

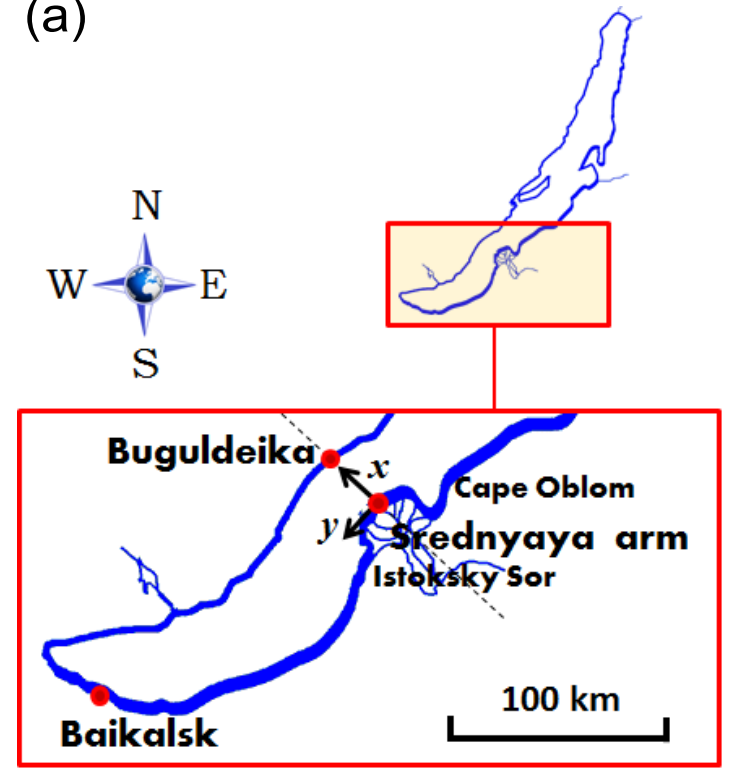

(b)

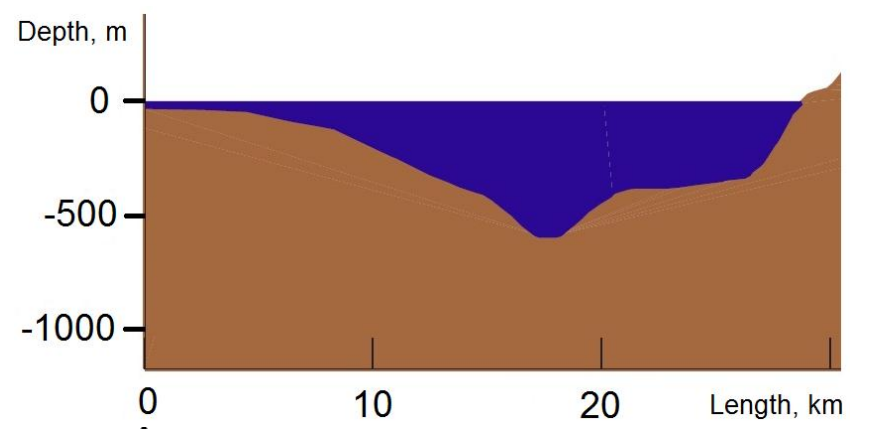

(c)

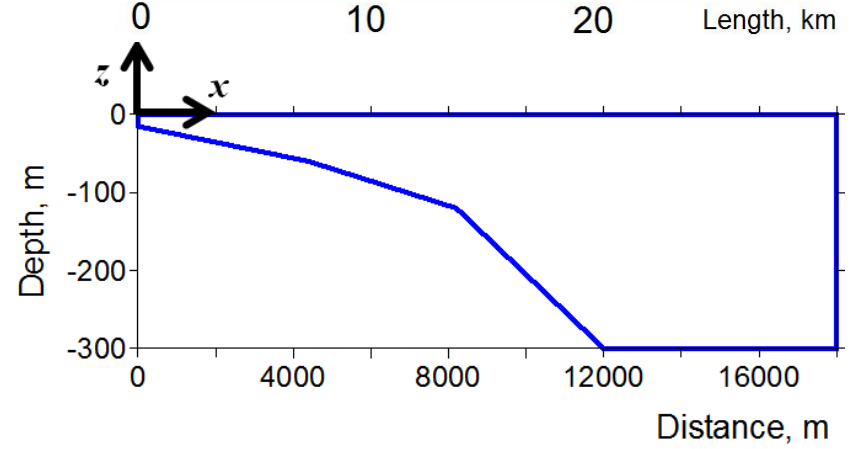

Figure 1. Srednyaya arm - Buguldeika cross-section: a - Lake Baikal cross-section; $b$ - bottom topography; c-calculation domain

In June the average values of vertical distribution of temperature in South Basin of Lake Baikal vary from 3.06 to $3.20^{\circ} \mathrm{C}$ in the upper 100-m layer (Shimaraev et al., 1994). On the basis of these observed data, we assumed a constant

temperature equal to $3^{\circ} \mathrm{C}$ as initial condition in the numerical experiment. The initial water temperature in the Selenga River is $5^{\circ} \mathrm{C}$ and increases by $0.4^{\circ} \mathrm{C}$ every day, which corresponds to the real temperature regime in May (Ivanov, 2012). The river flows into the lake at a velocity of $0.015 \mathrm{~m} / \mathrm{s}$. This value reflects the average flow velocity at the average annual water discharge in the Selenga of $1000 \mathrm{~m}^{3} / \mathrm{s}$ (Ivanov, 2012). Water mineralization in the lake is $S_{L}=0.096 \mathrm{~g} / \mathrm{kg}$, whereas it linearly increases from $0.140 \mathrm{~g} / \mathrm{kg}$ to $0.150 \mathrm{~g} / \mathrm{kg}$ in the river (Ivanov, 2012). The modeling

period is 30 days and corresponds to May conditions around the modeling area. The variable heat flux at the water surface includes long wave radiation as well as fluxes of latent and sensible heat (Section 2.4). Wind stress is taken into account at the free surface, $H_{g e o}=0.1 \mathrm{~W} / \mathrm{m}^{2}$ geothermal heat is taken into account at the bottom. Geographic latitude $\varphi=52.33^{\circ}$ corresponds to the Srednyaya arm - Buguldeika cross-section and the angle between the chosen cross section and East is $142^{\circ}$.

Because our aims are to study the interactions between the river and the lake, and the atmosphere and the upper layers of body of water, we consider the computational domain with length of $18 \mathrm{~km}$ and depth of $300 \mathrm{~m}$ (Fig. 1c). The open boundary at the river outflow (at the left boundary) is $15 \mathrm{~m}$ deep. The calculation domain (Fig. 1c) is covered by a uniform orthogonal grid with steps $h_{x}=50 \mathrm{~m}$ and $h_{z}=5 \mathrm{~m}$. The time step $\Delta t=60 \mathrm{~s}$. The calculations were made on a supercomputer, SKIF Cyberia, at Tomsk State University. 


\subsection{Heat fluxes and wind stress on the lake surface}

The above non-hydrostatic model takes into account the diurnal variability of the meteorological factors (Fig. 2) affecting the lake water surface. Data from the weather conditions archive of the Baikalsk meteorological station

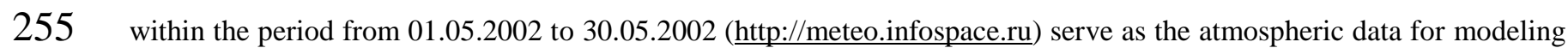
the thermal bar in Lake Baikal. The meteorological station is located close to the area of interest (Fig. 1a). Figure 2 represents the diagrams of air temperature, relative humidity, atmospheric pressure, humidity and wind velocity close to the lake surface obtained as a result of the linear interpolation in time. The data sampling interval is 6 hours (the original meteorological measurements are indicated in Figure 2 by symbols).

Short- and longwave radiation, fluxes of latent and sensible heat as well as the wind action at the water-air interface are calculated from the available observation data (Section 2.4). Figure 3 shows heat flux component variations in May 2002.

In Fig. 3, long wave radiation, $H_{l w}$, is both positive and negative. During the first 20 days of the month, $H_{l w}$ varies from -92 to $21 \mathrm{~W} / \mathrm{m}^{2}$, whereas in the final 10 days it increases to $49 \mathrm{~W} / \mathrm{m}^{2}$. The latent heat flux $H_{L}$ varies from

$265-40$ to $0 \mathrm{~W} / \mathrm{m}^{2}$ over the entire period. During the last 20 days of the month, the sensible heat flux $H_{S}$ is mostly positive due to an increase in the daily average temperature of the air.

Comparing the various heat flux components at the lake surface, the shortwave radiation is the dominant contribution to the thermal regime. If the total heat flux at the lake surface is averaged on a per day basis one can obtain a value slowly increasing from $103 \mathrm{~W} / \mathrm{m}^{2}$ at the beginning of the month up to $239 \mathrm{~W} / \mathrm{m}^{2}$ at the end of the month. Due to 270 the predominance of days with high clouds, the monthly mean value of the total heat flux was $171 \mathrm{~W} / \mathrm{m}^{2}$ which is below the constant values of the total heat flux applied by other authors in studies of the thermal bar effect: $250 \mathrm{~W} / \mathrm{m}^{2}$ (Holland et al., 2001), $260 \mathrm{~W} / \mathrm{m}^{2}$ (Vasiliev et al., 1998). 
Air temperature

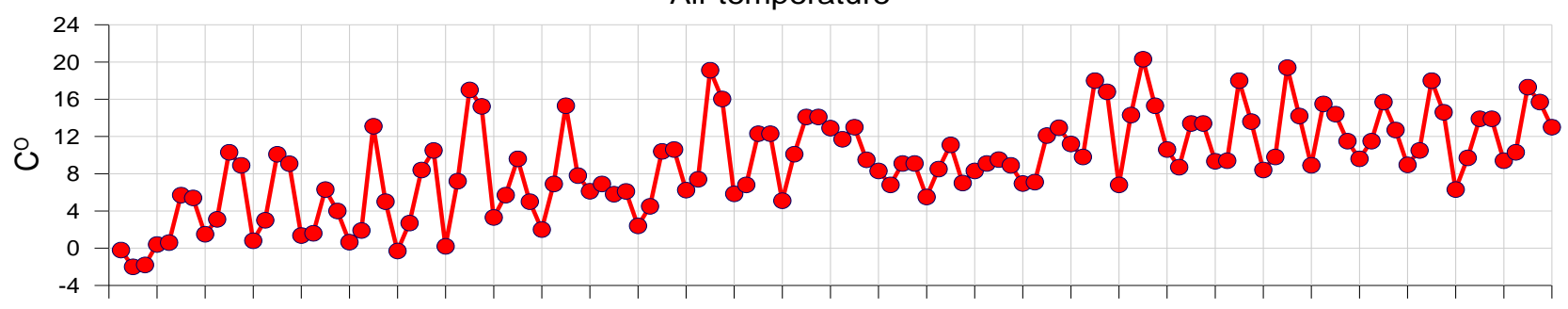

Relative humidity
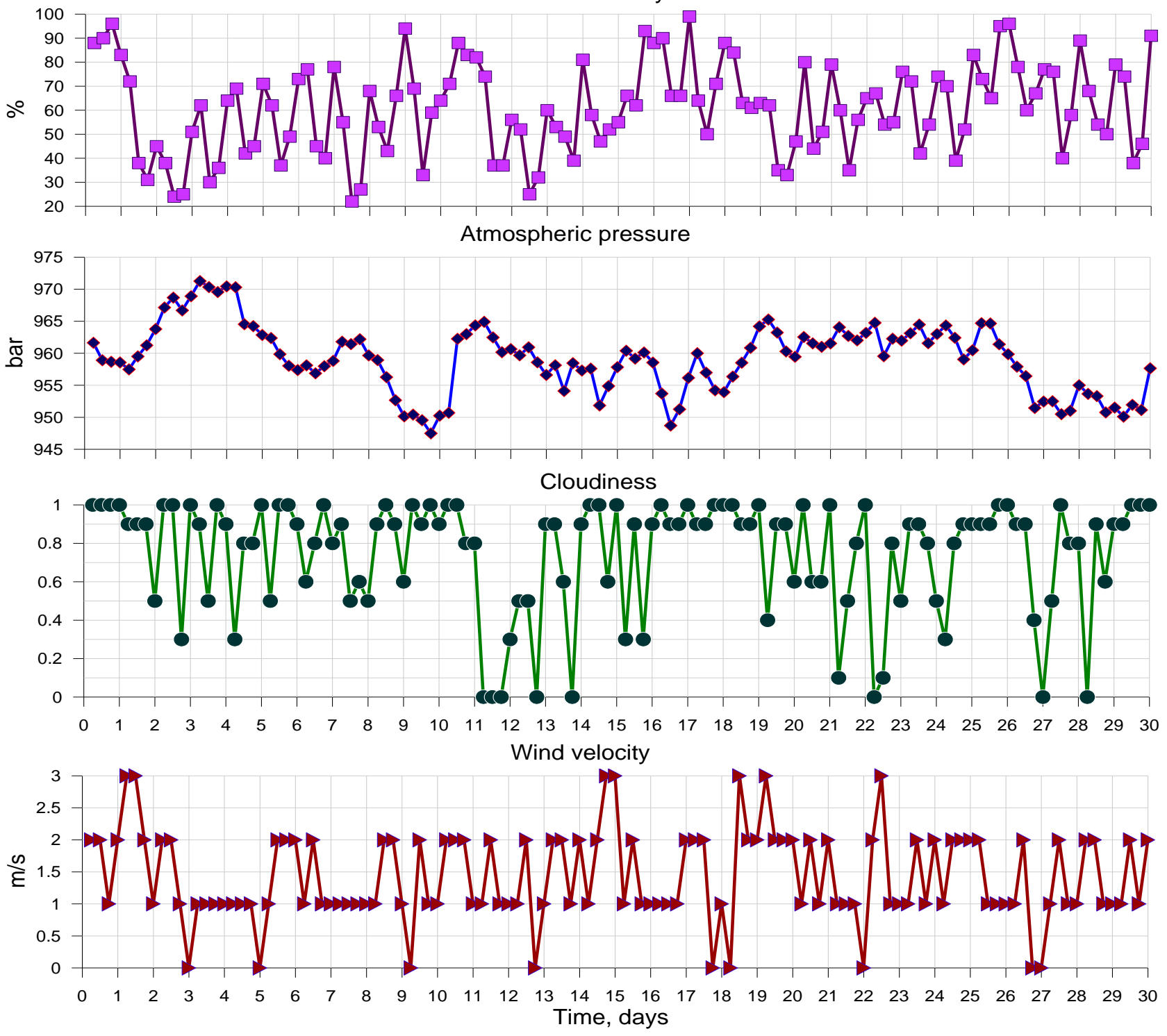

Figure 2. Air temperature, relative humidity, atmospheric pressure, cloudiness, and wind velocity from 01.05.2002 to 30.05 .2002 (UTC time) 

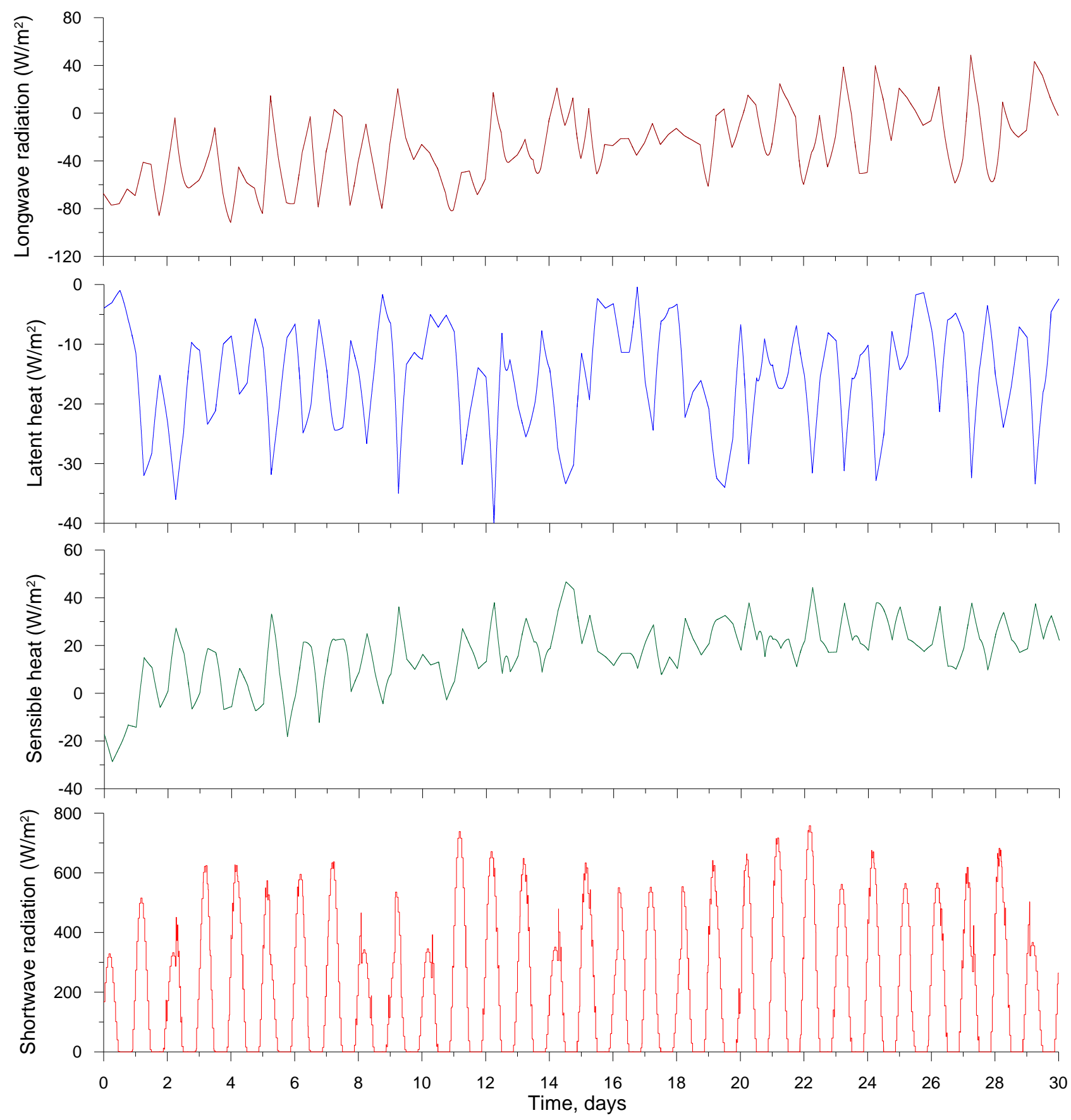

Figure 3. Heat flux components calculated based on atmospheric data of the Baikalsk meteorological station from 01.05.2002 to 30.05.2002 (UTC time)

\subsection{Results of simulation of spring riverine thermal bar development in Lake Baikal}

Figures 4-7 represent the thermo-hydrodynamic parameters of the investigated geophysical process calculated for the conditions described above in section 4.1. Figure 4 represents temperature and velocity longitudinal component fields and velocity vector field on the fifth day of the simulation of spring riverine thermal bar development. The location of the maximum density temperature (Fig. 4a, the maximum density temperature profile is marked yellow) shows that the thermal bar front shifts to approximately $3.5 \mathrm{~km}$ from the Selenga River mouth on the fifth calculation 
day. The velocity vector field (Fig. 4b) and longitudinal velocity isolines (Fig. 4c) demonstrate the downwelling of more mineralized river water and the fluid circulation in the area of the thermal bar front. Although density differences due to mineralization are greater than those due to temperature variations at this stage, the location of the downwelling (around the $4^{\circ} \mathrm{C}$ isotherm) appears to be controlled by cabbeling. Mixing of the colder water from the open lake with the warmer, more mineralized, river water (which has reached nearly $8^{\circ} \mathrm{C}$ on the fifth day) produces water of maximum density which sinks in quite a narrow region, the thermal bar. This water reaches the bed of the lake at a depth of about 50 meters and then continues moving down the bed slope towards the deeper part of the lake. At the same time, the downwelling induces a surface flow of cold water from the open lake towards the thermal bar, thus maintaining the circulation. The isotherms are close to vertical, which is related to the Coriolis force.

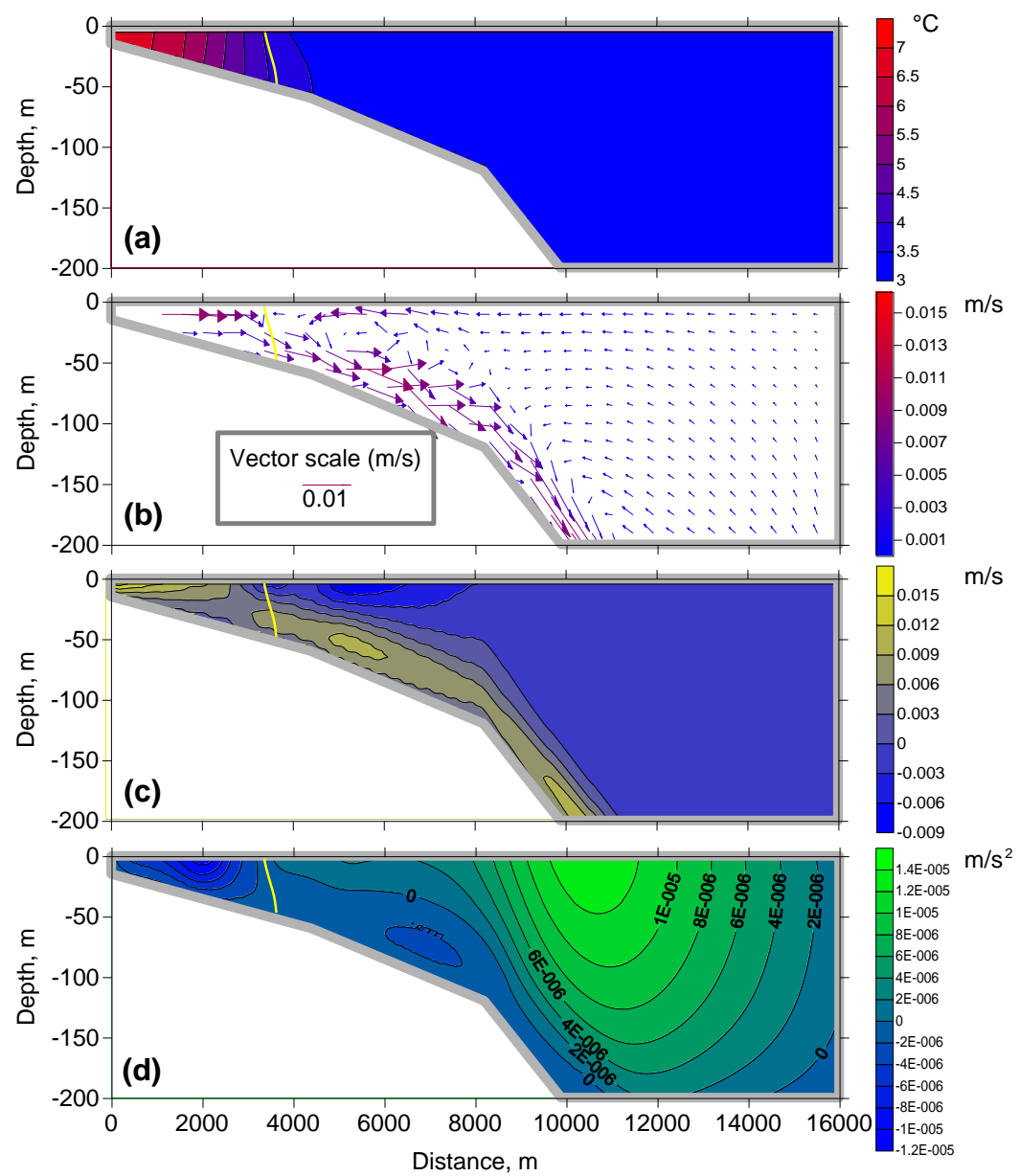

Figure 4. Isotherms (a), vector velocity field (b), longitudinal velocity component isolines (c), and longitudinal Coriolis force component (d) on the 5th day of calculation

It should be noted that the longitudinal component of velocity decreases within the region $2.5-2.8 \mathrm{~km}$ from the river inflow. This is related to the retarding action of the longitudinal component of the Coriolis force in this region. 300 The Coriolis force longitudinal component in the zone up to $3.8 \mathrm{~km}$ from the river mouth is negative (Fig. 4d). That is, in this zone the Coriolis force is directed towards the shore, and, thereby, it is opposite to the thermal bar front motion. 
In the remaining part of the calculation domain, the longitudinal component of the Coriolis force is mostly positive.

Figure 5 demonstrates water density profiles along the lake at a depth of $7.5 \mathrm{~m}$ calculated at four times. The figure shows that density was changing within a very narrow area close to the Selenga River mouth at the beginning of

305 the modeled process. However, significant density gradients occurred at a distance up to $5 \mathrm{~km}$ along axis $O x$ in as little as 10 days of modeling. River water density decreases quickly during the period of interest. At the same time, the water density near the lake surface increases as the lake warms towards the temperature of maximum density. The maxima in the density profiles occur in the thermal bar area.

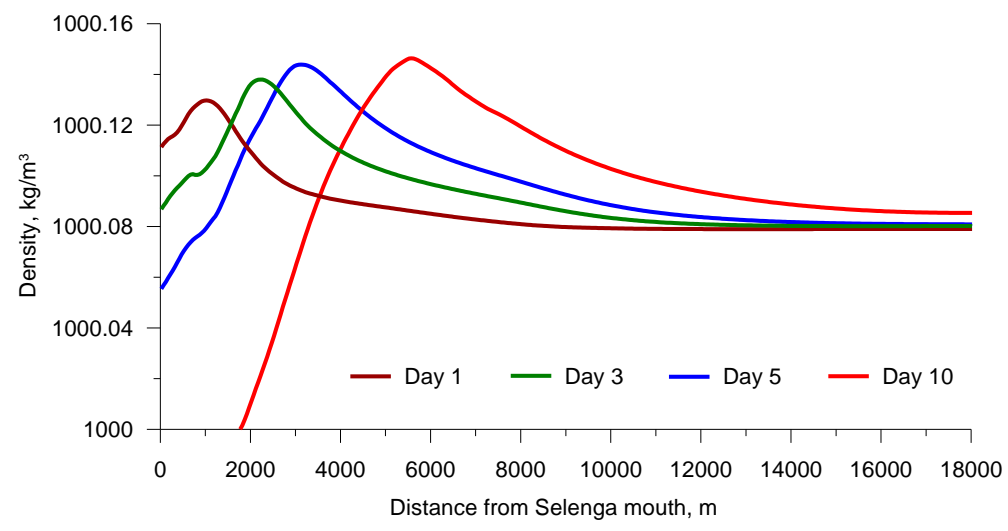

Figure 5. Calculated density values at a depth of $7.5 \mathrm{~m}$

The thermal bar appears where water temperature is close to the maximum density temperature. Consider the function $T-T_{M D}(p, S)$, where $T_{M D}(p, S)$ is the maximum density temperature. Then the zero contour of the function $T$ $T_{M D}(p, S)$ will correspond to the maximum density temperature. Figure 6 represents the distribution of the function $T$ -

$315 T_{M D}(p, S)$. River water entering the lake with a higher temperature evidently contributes to generation of the thermal bar and its further propagation towards the center of the lake. It should be noted that the isotherms depicted in Fig. 6 qualitatively correspond to the field data (Rossolimo, 1957) (Fig. 7).
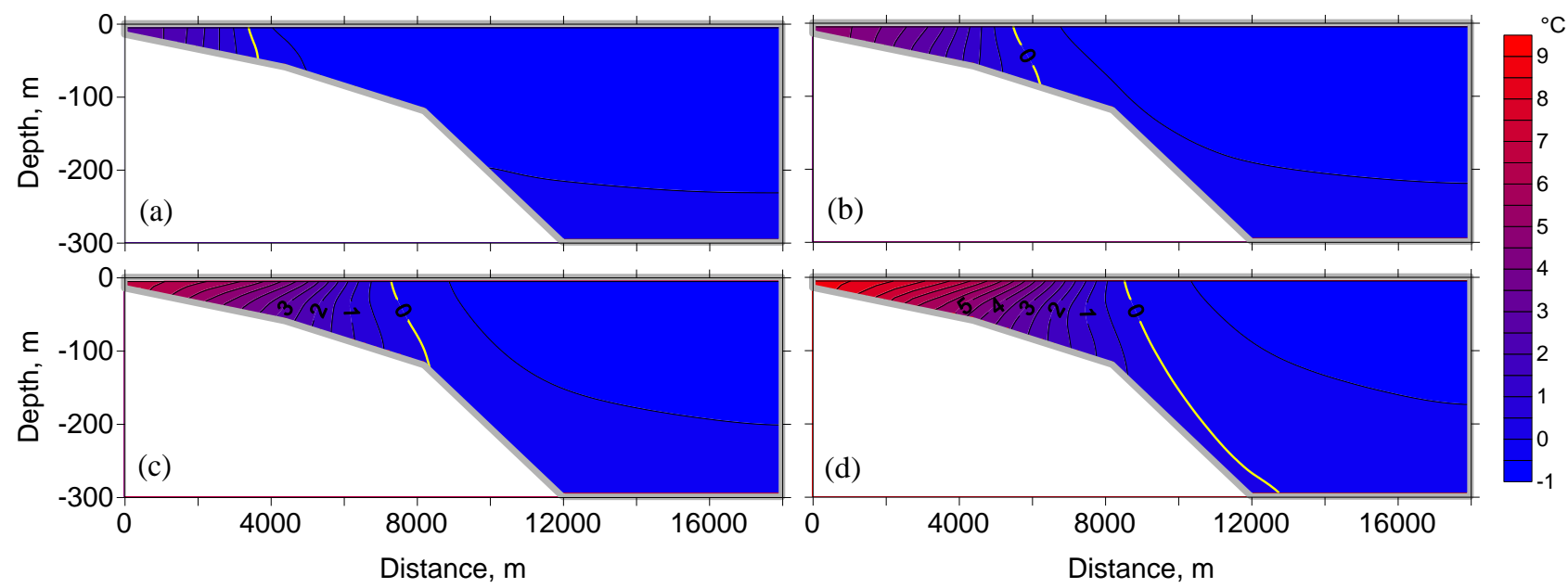

Figure 6. Isolines of function $T-T_{M D}(p, S)$ after $5(a), 10(b), 15(c)$ and $20(d)$ days 


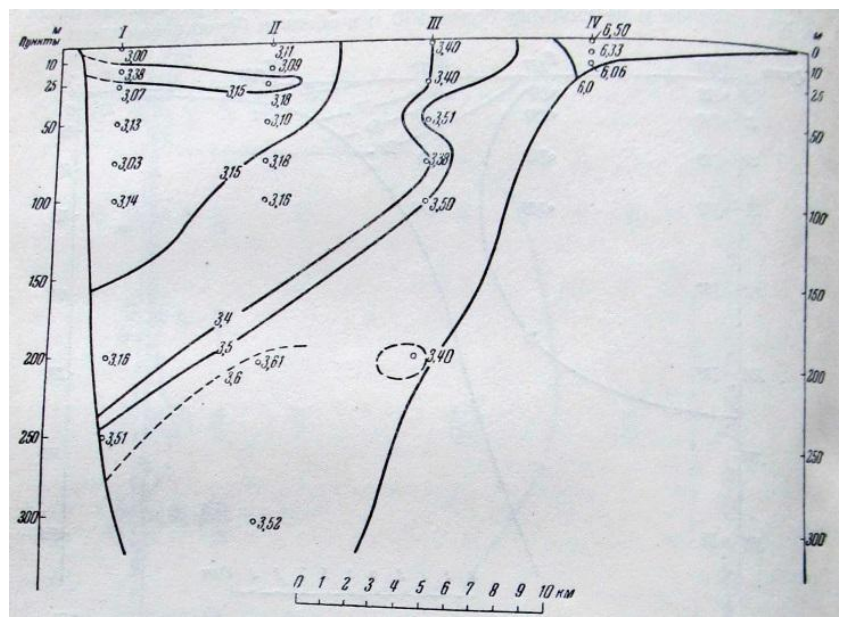

Figure 7. Bugildeika-Selenga mouth temperature cross-section during the spring heating of Lake Baikal, 1925 (Rossolimo, 1957). Selenga mouth is located at the right side

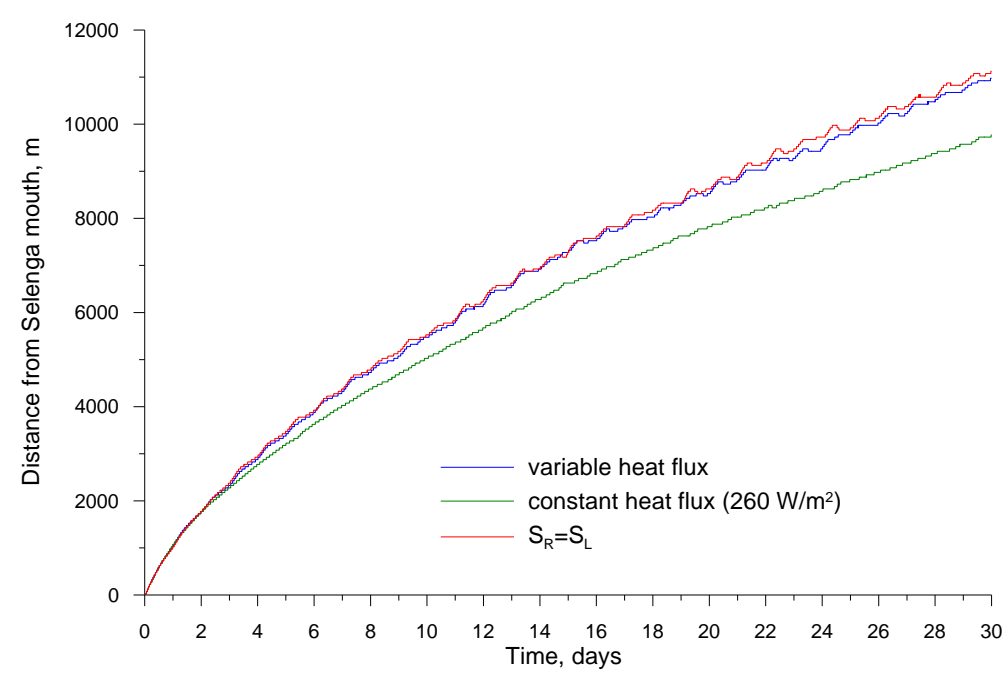

Figure 8. Dynamics of maximum density temperature horizontal displacement at the lake surface

A diagram of the location of the maximum density temperature on the lake surface as a function of time clearly shows

the thermal bar propagation rate. Figure 7 demonstrates the dynamics of thermal bar development based on the position of the maximum density temperature with the parameterization of heat flux components on the lake surface as described in section 4.2 (Fig. 8, blue line) and with a constant value of the heat flux equal to $260 \mathrm{~W} / \mathrm{m}^{2}$ (Fig. 8, green line) on the free surface in the same conditions of the river inflow. The diagrams show that the variable heat flux significantly influences thermal bar development (Fig. 8). Despite a lower value of the monthly mean total heat flux $\left(171 \mathrm{~W} / \mathrm{m}^{2}\right)$, the average thermal bar movement velocity with the variable heat flux is higher because of the influence of the river inflow: the impulse and thermal energy of the river accelerate thermal bar propagation during the day time and prevent backward thermal bar movement at night, although as the thermal bar moves further from the inflow the influence of the river weakens. Based on comparison of the diagrams, we can conclude that the boundary condition on the free 
surface with the constant heat flux simplifies the concept of the process of thermal bar evolution. The results of 340 calculations that account for the diurnal variation of meteorological data provide evidence that thermal bar propagation decelerates at night and thermal bar reverse motion (towards the shore) is possible within some particular areas at night due to cooling. This finding is in agreement with the recently published results of methodological investigation of the classical (without river inflow) thermal bar in the nighttime (Blokhina, 2014). The increase of the oscillatory amplitude with time indicates that the influence of the diurnal variation increases with distance from the mouth of the Selenga.

345 Factors that may contribute to this are firstly, that the early stages of thermal bar development are dominated by the river inflow rather than the variation of meteorological parameters, and secondly, that the horizontal temperature gradient decreases with distance from the shore (Farrow, 1995a) so that the diurnal forcing variation will lead to greater excursions of the $4^{\circ} \mathrm{C}$ isotherm when it is further offshore. It is also notable that the increase of the total heat flux mean value (Fig. 4) leads to the strengthening of the general trend of thermal bar propagation in the central part of the lake.

350 Therefore, diurnal variation of atmospheric characteristics is very important to consider in thermal bar modeling.

River inflow salinity variation has effect on the location of the maximum density temperature. The calculations carried out with the constant value of salinity, $0.096 \mathrm{~g} / \mathrm{kg}$, have shown that less mineralized river waters accelerate the propagation of the thermal bar in the lake's near-surface zone (Fig. 8, red line). The impact of the river salinity increases with increasing distance from the Selenga River (Fig. 8, compare the red and blue lines).

Wind stress influence on the velocity of the thermal bar upper boundary displacement was also studied. In particular a calculation was done with the values of $\tau_{\text {surf }}^{u}, \tau_{\text {surf }}^{v}$ assumed to equal zero during the whole modeling period. The outcomes of the comparison of the diagrams of thermal bar front displacement with time both with and without wind friction yield evidence of the insignificant influence of this effect on the movement of the water convergence boundary. It should be pointed out that numerical experiments in reservoirs of different depths showed that the higher wind speed is, the deeper the reservoir should be in order to get the zone of divergence of water masses close to maximum density temperature (Blokhina, 2015).

\subsection{Propagation of pollutant concentration in the zone of Selenga inflow into Lake Baikal}

A major pollution source in Lake Baikal is its largest tributary, the Selenga, providing over 50\% of the total river runoff. About $60 \%$ of the total pollution in Baikal is brought by the Selenga (http://rpn.gov.ru). Therefore, it is important to assess some qualitative characteristics of pollutant transport from the Selenga River to Lake Baikal. For this, the mathematical model includes the equation of pollutant concentration (6). We assume that the pollutants dissolved in the water neither rise to the surface nor are they deposited on the bed, i.e. the pollutant is neutrally buoyant. 
The overall dynamics of pollutant propagation in the area of the Selenga inflow into Lake Baikal is presented in Fig. 9.
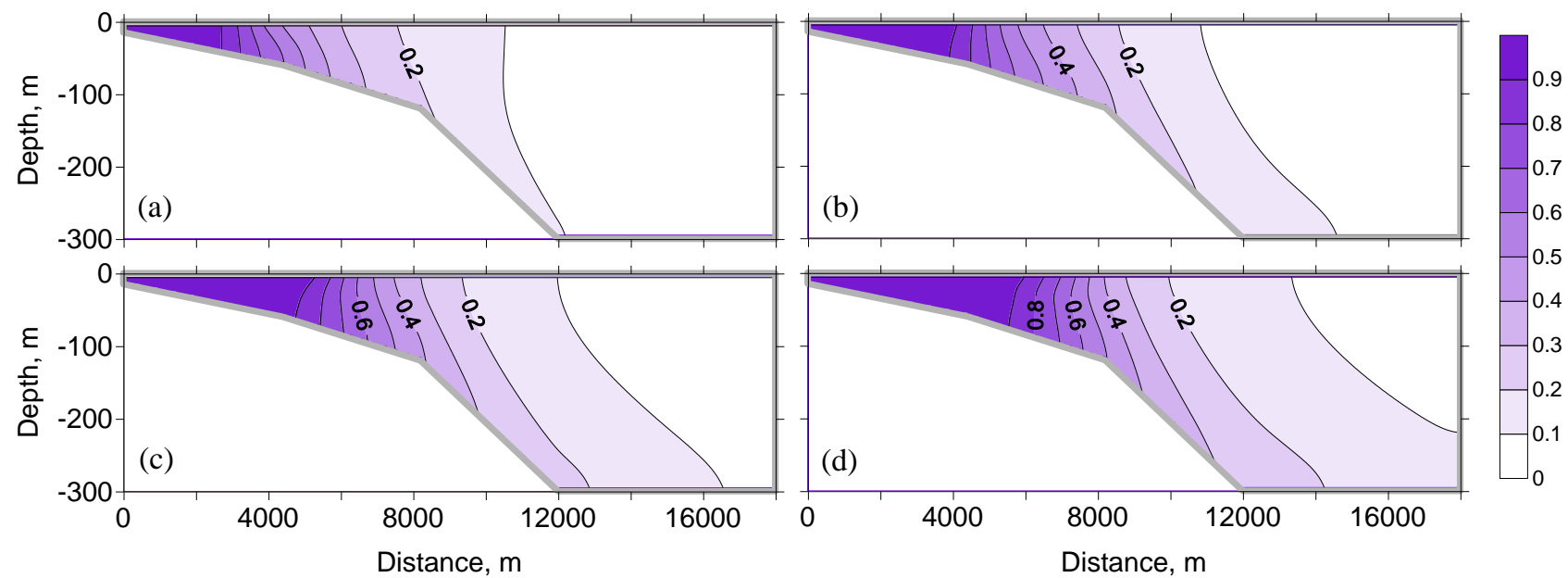

Figure 9. Concentration of pollutants from the Selenga River after 5 (a), 10 (b), 15 (c), 20 (d) days

The figure shows that due to the intensive vertical water circulation between the river inflow and the thermal bar, the pollutant is evenly distributed around the region near the inflow. In the deeper part of the lake, the pollutant carried by the more mineralized waters of the river inflow sinks to the near-bottom area of the lake. If the river inflow water density remained lower than the lake water density, as would happen without cabbeling, the pollutant would concentrate close to the lake surface. Such a pollutant distribution is specific to a winter period or early summer period (Carmack et al, 1979). So, we can make the conclusion that the thermal bar plays a leading role in pollutant propagation in the area of the Selenga inflow into Baikal. Hubbard and Spain (1973) have similarly observed that the propagation of dissolved materials from river runoff in Lake Superior is controlled by the thermal bar in spring.

\section{Conclusions}

The river inflow is the dominant influence on the thermal bar in its early stages, when it propagates at speeds around $1 \mathrm{~km} / \mathrm{day}$; later, the surface heat flux becomes dominant and the speed of propagation is reduced. Furthermore, the diurnal variation of shortwave radiation, a factor not usually considered in previous studies, causes thermal bar propagation to slow down or even reverse at night.

The distribution of pollutants entering Lake Baikal from the Selenga River is modeled by computing the concentration of a tracer introduced at the river inflow. The pollutants are well mixed through the depth of the lake inshore of the thermal bar, but further offshore they are carried down the slope of the lake bed with the flow of dense, mineralized water from the thermal bar. 


\section{Acknowledgements}

This work was supported by the Ministry of Education and Science of the Russian Federation (No. 5.628.2014/K). We are very grateful to Jean Kollantai, Senior Lecturer at Tomsk State University, for style review, to Lyudmila A. Lobaeva, Head Librarian at Limnological Institute of the Siberian Branch of the Russian Academy of Sciences, for electronic copy of Fig. 7, and to three anonymous reviewers whose comments improved this work.

\section{References}

Aleksandrova, M.P., Gulev, S.K., Sinitsyn, A.V., 2007. An Improvement of Parametrization of Short-Wave Radiation at the Sea Surface on the Basis of Direct Measurements in the Atlantic. Russian Meteorology and Hydrology 32(4) $245-251$.

Blokhina, N.S., 2014. A numerical model of spring thermal bar development and energy exchange between a water body and the atmosphere at night. Water Resources 41(4), 379-384.

Blokhina, N.S., 2015. The Influence of Wind on the Development of a Thermal Bar and Currents in Reservoirs of Different Depths during Ice Cover Melting. Moscow Univ. Phys. Bull. 70 (4), 319-325.

Blokhina, N.S., Ordanovich, A.E., Savel'eva, O.S., 2001. Model of formation and development of spring thermal bar. Water Resources 28(2), 201-204.

Bocharov, O.B., Ovchinnikova, T.E., 1998. On the thermo-gravity convection in the near-shore zone of a deep lake in the spring warming period. Computational Technologies 3(4), 43-12 (in Russian).

Carmack, E.C. and Farmer, D.M., 1992. Cooling processes in deep, temperate lakes: a review with examples from two lakes in British Columbia. J. Marine Res. 40, 85-111.

Carmack, E.C., 1979. Combined influence of inflow and lake temperatures on Spring circulation in a riverine lake. J. Phys. Oceanogr. 9, 422-434.

Carmack, E.C., Gray, C.B., Pharo, C.H.J., Daley, R.J., 1979. Importance of lake-river interaction on seasonal patterns in the general circulation of Kamloops Lake, British Columbia. Limnol. Oceanogr. 24(4), 634-644.

Chen, C., Millero, F., 1986. Precise thermodynamic properties for natural waters covering only limnologies range. Limnol. Oceanogr. 31(3), 657-662.

Danilov-Danilyan, V.I., 2009. Water - the strategic factor of long-term development of the Russian economy. Vestn. RAS 79(9), 789-798 (in Russian).

Elliott, G.H., 1971. A mathematical study of the thermal bar. Proc. 14th Conf. Great Lakes Res., 545-554.

Farrow, D.E., 1995. A numerical model of the hydrodynamics of the thermal bar. J. Fluid Mech. 303, $279-295$.

Farrow, D.E., 1995a. An asymptotic model for the hydrodynamics of the thermal bar. J. Fluid Mech. 289, $129-140$. 
Forel, F.A., 1880. La congélation des lacs suisses et sovoyards pendant l'hiver 1879-1880. 11 - Lac Léman. L’Écho des Alpes 3, 149-161.

Gbah, M.B. and Murthy, R.C., 1998. Characteristics of turbulent cross and alongshore momentum exchanges during a thermal bar episode in Lake Ontario. Nordic Hydrology 29, 57-72.

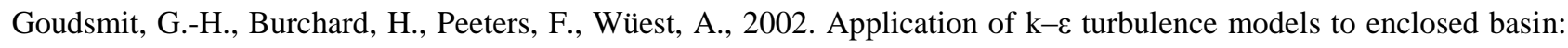
The role of internal seiches. J. Geophys. Res. 107(C12), 23-1-23-13.

Hodges, B., 1998. Heat budget and thermodynamics at a free surface: some theory and numerical implementation (revision 1.0c) ED 1300 BH. Center for Water Research, University of Western Australia.

Holland, P.R. and Kay, A., 2003. A review of the physics and ecological implications of the thermal bar circulation. Limnologica 33, 153-162.

Holland, P.R., Kay, A., Botte, V., 2001. A numerical study of the dynamics of the riverine thermal bar in a deep lake. J. Environ. Fluid Mech. 1(3), 311-332.

Holland, P.R., Kay, A., Botte, V., 2003. Numerical modelling of the thermal bar and its ecological consequences in a river-dominated lake. J. Mar. Syst. 43(1-2), 61-81.

Hubbard, D.W., Spain, J.D., 1973. The structure of the early Spring thermal bar in Lake Superior. Proc. 16th Conf. Great Lakes Research, 735-742.

Hurley, P., 2002. The air pollution model (TAPM) Version 2. Part 1 : technical description, CSIRO Atmospheric Research technical paper 55 .

Ivanov, V.G., 2012. Formation and evolution of the spring thermal bar due to river runoff (Selenga shallow of Lake Baikal), Report of Ph.D. Thesis (in Russian).

Ji, Z.-G., 2008. Hydrodynamics and Water Quality: Modeling Rivers, Lakes, and Estuaries, John Wiley \& Sons.

Killworth, P.D., Carmack, E.C., Weiss, R.F., Matear, R., 1996. Modeling deep-water renewal in Lake Baikal. Limnol. Oceanogr. 41(7), 1521-1538.

Kvon, V.I., Kvon, D.V., 1997. Numerical analysis of the deep penetration mechanism of surface waters during the spring-summer thermal bar. Computational Technologies 2(5), 46-56 (in Russian).

Leonard, B., 1979. A Stable and Accurate Convective Modeling Procedure Based on Quadratic Upstream Interpolation. Computer Methods in Applied Mechanics and Engineering 19(1), 59-98.

Malm, J., 1995. Spring circulation associated with the thermal bar in large temperate lakes. Nordic Hydrology 26(4-5), $331-358$.

Malm, J., Grahn, L., Mironov, D. and Terzhevik, A., 1993. Field investigation of the thermal bar in Lake Ladoga, Spring 1991. Nordic Hydrology 24, 339-358.

Orlanski, I., 1976. A simple boundary condition for unbounded hyperbolic flows. J. Comput. Phys., 21(3), 251-269. 
Ovchinnikova, T.E., Bocharov, O.B., 2007. The seasonal impact of inflow waters on the water exchange under steep incline conditions of bottom. Computational Technologies 12(6) 59-72 (in Russian).

Patankar, S., 1980. Numerical heat transfer and fluid flow, in: W.J. Minkowycz, E.M. Sparrow (Eds.), Hemisphere Publishing Corporation.

Rossolimo, L.L., 1957. Lake Baikal temperature regime, Publ House of the USSR Acad Sci, Moscow (in Russian).

Schmid, M., Budnev, M.N., Granin, N.G., Sturm, M., Schurter, M. and Wüest, A., 2008. Lake Baikal deepwater renewal mystery solved. Geophys. Res. Lett. 35, L09605.

Sherstyankin, P.P., Alekseev, S.P., Abramov, A.M. Stavrov, K.G., De Batist, M., Hus, R., Canals, M., Casamor, J.L., 2006. Computer-based bathymetric map of Lake Baikal. Dokl. Akad. nauk 408(1), 102-107.

Shimaraev, M.N., Granin, N.G. and Zhdanov, A.A., 1993. Deep ventilation of Lake Baikal waters due to Spring thermal bars. Limnol. Oceanogr. 38, 1068-1072.

Shimaraev, M.N., Granin, N.G., 1991. Concerning the stratification and convection mechanism in Baikal. Dokl. Akad. Nauk SSSR 321(2), 381-385 (in Russian).

Shimaraev, M.N., Verbolov, V.I., Granin N.G., Sherstyankin P.P., 1994. Physical Limnology of Lake Baikal: a Review. Irkutsk-Okayama.

Tsvetova, E.A., 1997. Numerical modelling of hydrodynamic processes responsible for propagation of contaminants in a deep basin. Computational Technologies 2(2), 102-108 (in Russian).

Tsvetova, E.A., 1998. Effect of the Coriolis force on convection in a deep lake: numerical experiment. J. Appl. Mech. Tech. Phys. 39(4), 593-599.

Tsvetova, E.A., 1999. Mathematical modelling of Lake Baikal hydrodynamics. Hydrobiologia 407, 37-43.

Tsvetova, E.A., 2011. Modelling of nonlinear instability mechanisms of Lake Baikal waters. Modern Problems of Applied Mathematics and Mechanics: Theory, Experiment and Applications (International Conference devoted to the 90th anniversary of professor Nikolai N. Yanenko), Novosibirsk (in Russian).

Tsydenov, B.O., Kay, A., Starchenko, A.V., 2015. Numerical modelling of pollutant propagation in Lake Baikal during the spring thermal bar. Procedia Computer Science 51(1), 2658-2662.

Tsydenov, B.O., Starchenko, A.V., 2013. Numerical model of river-lake interaction in the case of a Spring thermal bar in Kamloops Lake. Vestn. Tomsk. Gos. Univ. Mat. Mekh. 5(25), 102-115 (in Russian).

Tsydenov, B.O., Starchenko, A.V., 2014. Application of the two-parametric k- $\omega$ turbulence model for studying the thermal bar phenomenon. Vestn. Tomsk. Gos. Univ. Mat. Mekh. 5(31), 104-113 (in Russian).

Tsydenov, B.O., Starchenko, A.V., 2015. To the selection of heat flux parameterization models at the water-air interface for the study of the spring thermal bar in a deep lake. Proc. SPIE 9680, 96800H, 1-8. 
Vasiliev, O.F., Bocharov, O.B., Kvon, V.I., Ovchinnikova, T.E., Kvon, D.V., 1998. Numerical Modeling of Thermal Bars in Deep Lakes. Water Quality in Rivers and Lakes: Parallel Session.

Who Pollutes Baikal, The Federal Supervisory Natural Resources Management Service, http://rpn.gov.ru/node/1022 (Access Date: 06.11.2013, in Russian).

Wilcox, D., 1988. Reassessment of the scale-determining equation for advanced turbulence models. AIAA Journal 26(11), 1299-1310. 